history, and understand essential medicines as a shared global challenge that requires urgent action to avoid further preventable deaths.

\section{Youth Commission on Essential Medicines Policies $†$ c/o University of Bergen, P O Box 7800, N-5020 Bergen, Norway Kristine.Onarheim@uib.no}

† Members of the Youth Commission on Essential Medicines Policies are: Kristine Husøy Onarheim, Fiona Lander, Anna Roe Rasmussen, Rehan Adamjee, Ralph Kwame Akyea, Melissa J Barber, Jorge Browne, Nobel Cubahiro, Jordan D Jarvis, Sam Wing Sum Li, Shiva Raj Mishra, Motahareh Akhoondi Nasab, Oluwaseun Omobo, Reshma Ramachandran, Abhishek Sharma, and Alex Walker.

We declare no competing interests. The Youth Commission on Essential Medicines Policies was initiated by members of the student organisation Universities Allied for Essential Medicines. Of the members of the Youth Commission on Essential Medicines Policies, JDJ is employed at the Young Professionals Chronic Disease Network, a US non-for-profit organisation; $\mathrm{OO}$ worked as a consultant for WHO and for the Nigerian National Agency for Food and Drug Administration and Control; and RR received funding from the Swedish International Development Cooperation Agency, Johns Hopkins University, and the Robert Wood Johnson Foundation (pending) through her work at the IDEA initiative. We thank the Norwegian Forum for Global Health Research, the Norwegian Agency for Development Cooperation, and the
University of Bergen for funding the Youth Commission on Essential Medicines Policies. The funders had no role in preparation of this Comment. We thank Dilyara Nurkhametova for her contributions to the Youth Commission on Essential Medicines Policies and extend our thanks to our secretariat, Johanne Iversen and Arwin Timmermans.

1 Youth Commission on Essential Medicines Policies. Towards realising access to essential medicines for all: a vision for 2035. Nov 8, 2016. http://ycemp.com/ (accessed Oct 12, 2016).

2 Mishra SR, Li SWS, Onarheim KH, et al. Young people have a new vision for essential medicines. Lancet Diabetes Endocrinol 2016; 4: 733-34

3 Wirtz VJ, Hogerzeil HV, Gray AL, et al. Essential medicines for universal health coverage. Lancet 2016; published online Nov 7. http://dx.doi. org/10.1016/S0140-6736(16)31599-9.

4 Consultative Expert Working Group on Research and Development. Research and development to meet health needs in developing countries: strengthening global financing and coordination. Geneva: World Health Organisation, 2012. http://www.who.int/phi/CEWG_Report_5_April_2012. pdf (accessed Sept 15, 2016).

5 UN Secretary-General and Co-Chairs of the High-Level Panel. The United Nations Secretary-General's High-Level Panel on Access to Medicines Report: promoting innovation and access to health technologies. 2016. http://www.unsgaccessmeds.org/final-report/ (accessed Sept 15, 2016).

6 Gotham D, Onarheim KH, Barber MJ. How the MDGs gave up on measuring access to medicines. Lancet Glob Health 2016; 4: e296-97.

7 lyengar S, Tay-Teo K, Vogler S, et al. Prices, costs, and affordability of new medicines for hepatitis c in 30 countries: an economic analysis. PLoS Med 2016; 13: e1002032.

\title{
Grief is not a disease but bereavement merits medical awareness
}

Our 2007 review in The Lancet $^{1}$ showed ways in which bereavement is a topic of medical importance, despite the fact that grief, in line with George Engel's famous but often misinterpreted words, cannot be called a disease. ${ }^{2}$ Since then, developments in scientific knowledge make it pertinent to ask afresh: what do health-care professionals in general and medical practitioners in particular need to know about bereavement?

There is heightened risk of health problems after bereavement. Starting with the severest health effectsthe death of the bereaved person-one can die of "a broken heart", although this is a rare occurrence. Studies have extended beyond an earlier focus on spousal loss to provide information, for example, on the long-term effect of early parental death on mortality. ${ }^{3}$ Investigations of physical and psychological health problems confirm the broad range of troublesome reactions associated with bereavement that can result in increased use of medication, visits to doctors (although paradoxically, those most vulnerable may be the least inclined to seek help), and admissions to hospital. ${ }^{1,4}$ There are also non-medical difficulties that can lead to health consequences, for example, nutritional and sleep problems and economic trouble. Comorbidity, and distinctions or the apparent overlap between conditions, are still being unravelled-eg, with regard to complicated grief, depression, anxiety, and post-traumatic stress disorder. ${ }^{5}$ Research examining physiological mechanisms and neurobiological processes concurrent with bereavement has suggested there might be connections at this level with ill-health, particularly for complicated grief; biomarkers show some promise in distinguishing complicated grief from non-complicated grief, although application in clinical settings is not yet indicated. ${ }^{6}$

Complicated grief (also labelled "prolonged grief", among other terms) has by now been widely investigated, ${ }^{7}$ due partly to debate surrounding the inclusion of Persistent Complex Bereavement Disorder (PCBD) in the Diagnostic and Statistical Manual of Mental Disorders, Fifth Edition (DSM-5) as a bereavement-related clinical condition that does not have full diagnostic category status because it was evaluated as requiring further research. After provisional drafting of the eleventh revision of the International Classification of Diseases (ICD-11), complicated grief is expected to become a category of prolonged grief disorder, with 


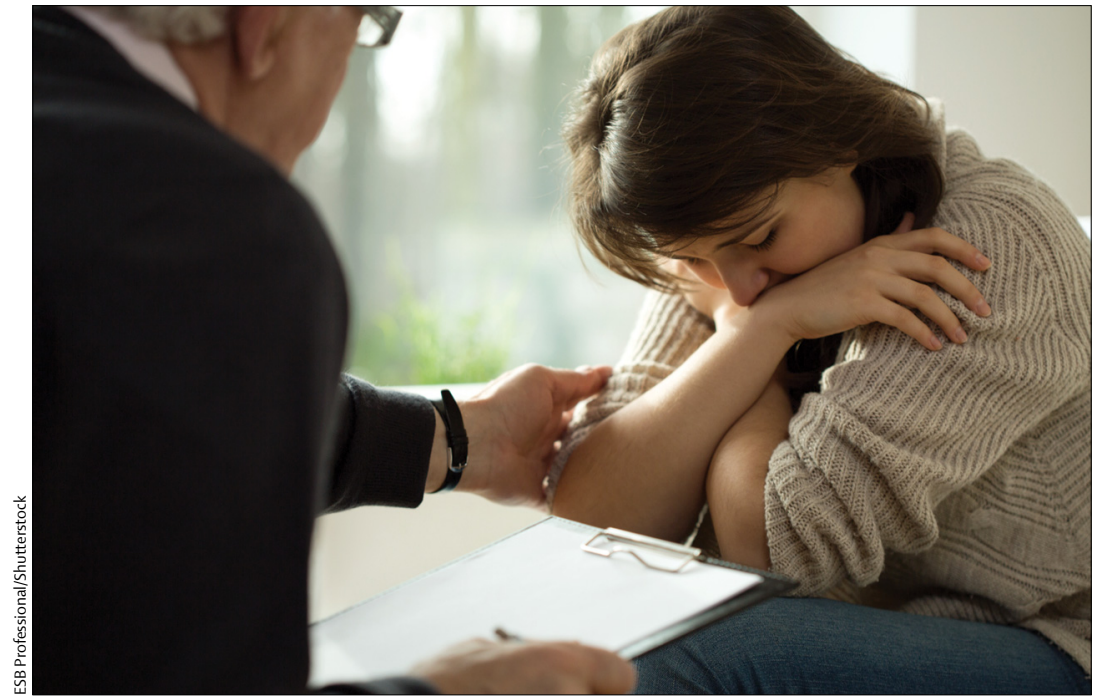

shorter bereavement duration ( $>6$ months) than PCBD ( $>12$ months) for specification of the diagnosis.? Debate about complicated grief criteria and the positive and negative effects of diagnosis continues. ${ }^{?}$

There is still agreement that only a minority of bereaved persons have complicated grief, with percentages varying below or above $10 \%$ depending on bereaved subgroup, bereavement duration, and complicated grief criteria. ${ }^{1}$ There is concern about potential overdiagnosisparticularly since "bereavement" is no longer specified as an exclusion criterion in diagnosing major depressive disorder early after loss ${ }^{7}-$ and ongoing debate about the extent of overall resilience among bereaved people. ${ }^{8}$ In general, most bereaved people eventually adapt well, although many suffer severely in the early weeks and months of bereavement; more time than the often-expected first calendar year is usually needed to adjust. Guidelines to help practitioners distinguish between normal and complicated grief have been proposed. ${ }^{5}$ Monitoring the need for practical and socioemotional support is also recommended, notably for the increasingly old bereaved in many societies, for minority groups, and for cases of "disenfranchised grief" (ie, losses which are unacknowledged without opportunity to publicly acknowledge, mourn, or receive support such as after miscarriages). ${ }^{9}$

Information on risk factors (ie, situational, intrapersonal, interpersonal, coping) can alert health-care professionals to people likely to have negative health effects of bereavement. ${ }^{10}$ We still do not know how risk factors relate to different health outcomes or how factors interact to increase or lower risk (eg, circumstances of death with personality). However, there are new understandings of the nature of adaptive so-called grief work (an entrenched notion in theories of grief which proposes one must confront aspects of the loss experience to come to terms with it) versus maladaptive, persistent ruminative processing, with the former identified as confrontational and the latter regarded as avoidant of the reality of loss. ${ }^{11}$ In this context, it is important to note that the so-called stage theory of grief should not be "prescribed" to any bereaved person, since the approach is not valid on several counts and bereaved people can be harmed by thinking they should go through the stages. ${ }^{12}$ There are alternative approaches which better represent grief and grieving processes. ${ }^{9}$

More is now known about the need for, and impact of, psychological treatments in general (ie, counselling and therapy). There is continued support for the view that bereaved people do not, just because they have become bereaved, need routine referral to such interventions. Most efficacy research has focused on the effect of psychological bereavement intervention in complicated grief, and to a lesser extent in depression, with some positive results reported. ${ }^{7.13}$ However, more evidence is needed about the efficacy of psychological interventions for bereaved persons at high-risk of health complications, including complicated grief. More precise identification of risk groups is essential to clarify what works for whom, and precisely when such treatment is needed. In general, the emphasis is now on evidence-based, solution-focused, short-term, cost-efficient psychological treatments. Further studies need to establish the extent to which supportive psychological interventions reduce the increased costs of bereavement to health-care systems. ${ }^{14} \mathrm{~A}$ major thrust of current research is to examine core processes that bring about change in specific interventions. Researchers have also begun to explore the usefulness of online interventions.? In the past, psychotropic medication such as antidepressants was not recommended by experts for bereaved persons, but is now at times prescribed for people with complicated grief, sometimes in combination with psychotherapy. However, although progress is being made, ${ }_{1}^{13}$ caution is still required because of the need to further substantiate the efficacy of such treatment approaches?

Looking across the decades, it becomes evident that the nature of bereavement research has evolved, influencing 
knowledge about grief in a medical context. Even in the time since our 2007 review, there has been some expansion and improvements in research designs and techniqueseg, implementation of daily monitoring systems, experimental techniques in laboratory studies, and use of statistical approaches such as symptom-network analyses and multilevel techniques. The availability of the internet necessitates further examination of its use for information, commemoration, communication, and intervention, with interest in how these impact on adjustment. ${ }^{15}$

Engel's plea was for a biopsychosocial medical model, not for grief-as-a-disease. ${ }^{2}$ He used bereavement as a case study to illustrate his passionate belief in the need to expand ideas about how diseases are defined with grief being a legitimate topic for medical scientists. Incorporation of bereavement into the realm of topics of medical concern is as necessary today as it was over half a century ago when Engel wrote his paper. Improved awareness can lead to provision of appropriate, probably cost-effective health care to only those bereaved people who need it.

\footnotetext{
*Margaret Stroebe, Wolfgang Stroebe, Henk Schut, Kathrin Boerner

Department of Clinical Psychology, Utrecht University, Utrecht 3508TC, Netherlands (MS, HS); Department of Social and Organizational Psychology (WS) and Department of Clinical Psychology and Experimental Psychopathology (MS), University of Groningen, Groningen, Netherlands; and Department of Gerontology, McCormack Graduate School, University of Massachusetts Boston, Boston, MA, USA (KB) m.s.stroebe@uu.nl
}

We were the authors of the Lancet 2007 review on health outcomes of bereavement. ${ }^{1}$ We declare no other competing interests.

1 Stroebe $\mathrm{M}$, Schut $\mathrm{H}$, Stroebe W. Health outcomes of bereavement: a review. Lancet 2007; 370: 1960-73.

2 Stroebe M. Is grief a disease? Why Engel posed the question. OMEGA: J Death and Dying 2015; 71: 272-79.

3 Li J, Vestergaard M, Cnattingius S, et al. Mortality after parental bereavement in childhood: a nationwide cohort study from three Nordic countries. PLoS Med 2016; 11: e1001679.

4 Parkes CM, Prigerson H. Bereavement: studies of grief in adult life. London: Routledge, 2013

5 Zisook S, Iglewicz A, Avanzino J, et al. Bereavement: course, consequences, and care. Curr Psychiatry Rep 2014; 16: 482-92.

6 O'Connor M-F. Physiological mechanisms and the neurobiology of complicated grief. In: Stroebe M, Schut H, van den Bout J, eds. Complicated grief: scientific foundations for health care professionals. London: Routledge, 2013: 204-18.

7 Doering B, Eisma M. Treatment for complicated grief: state of the science and ways forward. Curr Opin Psychiatry 2016; 29: 286-91.

8 Galatzer-Levy I, Bonanno G. It's not so easy to make resilience go away: commentary on Infurna and Luthar (2016). Perspect Psychol Sci 2016; 11: 195-98.

9 Doka K, Tucci A. Beyond Kübler-Ross. New perspectives on death, dying and bereavement. Washington, DC: Hospice Foundation of America, 2011.

10 Burke L, Neimeyer RP. Prospective risk factors for complicated grief: a review of the literature. In: Stroebe M, Schut H, van den Bout J, eds. Complicated grief: scientific foundations for health care professionals. London: Routledge, 2013: 145-61

11 Eisma M, Stroebe M, Schut H, Stroebe W, Boelen P, van den Bout J. Avoidance processes mediate the relationship between rumination and symptoms of complicated grief and depression following loss. J Abnorm Psychol 2013; 122: 961-70.

12 Stroebe M, Schut H, Boerner K. Cautioning health care professionals: bereaved persons are misguided through the stages of grief. OMEGA: J Death and Dying (in press).

13 Shear K, Reynolds CF 3rd, Simon NM, et al. Optimizing treatment of complicated grief: a randomized clinical trial. JAMA Psychiatry 2016; 73: 685-94.

14 Rolden $\mathrm{H}$, van Bodegom D, Westendorp R. Changes in health care expenditure after the loss of a spouse: data on 6,487 older widows and widowers in the Netherlands. PLoS One 2014; 9: e115478.

15 Walter T, Hourizi R, Moncur W, Pitsillides S. Does the Internet change how we die and mourn? Overview and analysis. OMEGA: J Death and Dying 2012; 64: 275-302

\section{A thank you to The Lancet's peer reviewers in 2016}

With the new year under way, it is fitting to pause and express thanks to the almost 2300 reviewers (appendix) who took time to comment on Lancet manuscripts in 2016. Many on repeated occasions and across the Lancet family of journals.

Each peer review tells a story. Beyond the rudiments of quality, clinical value, and novelty related to the submission, peer reviews share the intellect and personality of the reviewer. They often challenge authors and editors alike with broader perspectives of health and provocative assessments of how a particular study could change thinking. This combination adds richness and diversity to The Lancet's content and assures its relevance to an international general readership.

The willingness, timeliness, and thoroughness of reviewers is appreciated by authors and editors. Although not every suggestion may be acted upon, they form a vital part of decision making and of subsequent editing, and are never taken for granted. Thank you for your support over the past year.

The Editors of The Lancet

The Lancet, London EC2Y 5AS, UK 